\title{
Review
}

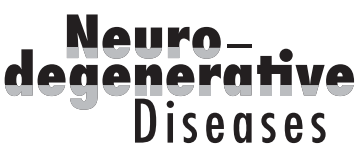

\section{A Hypnic Hypothesis of Alzheimer's Disease}

\author{
Camilla N. Clark Jason D. Warren \\ Dementia Research Centre, UCL Institute of Neurology, University College London, London, UK
}

\section{Key Words}

Sleep $\cdot$ Alzheimer's disease $\cdot$ Neurodegeneration $\cdot$ Default mode network

\begin{abstract}
Background: Understanding the pathophysiology of Alzheimer's disease (AD) is of fundamental importance for improved diagnosis, monitoring and ultimately, treatment. $\mathbf{O b}$ jective: A role for the sleep-wake cycle in the pathogenesis of AD has been proposed, but remains to be worked out in detail. Methods: Here we draw together several lines of previous work to outline a 'hypnic hypothesis' of AD. Results: We propose that altered function of brainstem neurotransmitter pathways associated with sleep, promotes regionally specific disintegration of a cortico-subcortical 'default mode' brain network that is selectively vulnerable in AD. Conclusion: The formation of a dynamic toxic state within this vulnerable network linked to sleep-wake disruption, would in turn lead to failure of synaptic repair, increased transmission of pathogenic misfolded proteins and a self-amplifying neurodegenerative process. We consider the evidence for this hypnic hypothesis and the implications that follow on from it.
\end{abstract}

Copyright $\odot 2013$ S. Karger AG, Basel

\section{Introduction}

Understanding the pathophysiology of Alzheimer's disease $(\mathrm{AD})$ is of fundamental importance for improved diagnosis, monitoring and ultimately, treatment of this devastating condition. Molecular biological, biochemical and neuroimaging studies have yielded a substantial body of data on the causes and evolution of AD [1-5], whilst the concept of a vulnerable distributed brain network provides a framework for explaining how molecular events might scale up to a clinical phenotype [6-9]. It is increasingly clear that $\mathrm{AD}$ has a protracted prodromal phase prior to clinical onset during which potentially pathogenic factors could operate and might have cumulative effects [5].

On a biochemical level, synaptic alterations are hypothesised to play a key role in the pathogenesis of many neurodegenerative diseases, including AD [9-11]. Such alterations may promote the transfer of pathogenic molecular species (in particular, $\beta$-amyloid oligomers) leading to the diffusive spread of misfolded proteins (in particular, hyperphosphorylated tau) throughout a vulnerable, distributed brain network, the so-called 'default mode network' (DMN) that appears to be integral to the operation of the normal resting brain [1216]. Most accounts of synaptic dysfunction in $\mathrm{AD}$ emphasise molecular and biochemical events impacting on synaptic physiology via a loss of structural integrity [11, 17]. However, an alternative (and by no means mutually exclusive) possibility is the promotion of synaptic damage by altered patterns of synaptic activity and excitotoxicity [18]. A fundamental example of a pervasive, phasic alteration in synaptic activity is the circadian sleep-wake cycle, which is associated with profound changes in many aspects of cellular and synaptic function $[19,20]$.

\begin{tabular}{ll}
\hline KARGER & $\begin{array}{l}\text { (c) 2013 S. Karger AG, Basel } \\
1660-2854 / 13 / 0124-0165 \$ 00.00 / 0\end{array}$ \\
E-Mail karger@karger.com & $\begin{array}{l}\text { This is an Open Access article licensed under the terms of } \\
\text { the Creative Commons Attribution 3.0 Unported license } \\
\text { (CC BY 3.0) (www.karger.com/OA-license-WT), appli- } \\
\text { cable to the online version of the article only. }\end{array}$
\end{tabular}

Dr. J.D. Warren

Dementia Research Centre, UCL Institute of Neurology

University College London, 8-11 Queen Square

London WC1N 3BG (UK)

E-Mail jason.warren@ucl.ac.uk 
The precise implications of sleep-wake alterations for the pathogenesis of neurodegenerative diseases such as $\mathrm{AD}$ remain to be defined. However, converging evidence drawn from molecular biology, sleep neuroscience [2134] and clinical neurology [35-42] suggests that sleep may interact in diverse and important ways with the pathophysiology of AD. Ramifications of long-term disruption in the sleep-wake cycle could include synaptic overactivity and excitotoxicity [10,21,43-45], impaired synaptic pruning [46], failure of synaptic scaling and homeostatic responses $[19,20,27,47-51]$, transmission of pathogenic proteins ( $\beta$-amyloid and tau) $[9,15,16]$, and disruption of neural circuitry in the vulnerable DMN [6, $8,12,21,52,53]$. Such alterations might in turn underpin or contribute to the cognitive syndrome that characterises $\mathrm{AD}$.

\section{A 'Hypnic Hypothesis' of AD}

Although a role for the sleep-wake cycle in the pathogenesis of $\mathrm{AD}$ has been proposed previously [26, 33, 45, 54 ], this idea has received relatively little attention; however, it has become increasingly compelling in light of recent findings in human molecular and neuroimaging studies. Here we draw together several lines of previous work $[1,2,8,10,12-14,21,33,35-37,39,42,43,55-67]$ to outline a hypnic hypothesis of $\mathrm{AD}$ pathophysiology. $\mathrm{A}$ prima facie case for the hypothesis rests on accumulating evidence that sleep-wake cycle disturbances are significant in $\mathrm{AD}$, and may track disease evolution [35-37, 39, $55,58,61,62,67]$. The key features of the hypothesis we propose and predictions that follow from it are outlined in table 1 and figure 1.

Ascending neurotransmitter projection pathways play a key role in initiating and maintaining the brain state shifts that underpin sleep and wakefulness [68]. Aminergic and cholinergic pathways originating in brainstem nuclei govern thalamocortical activity changes that in turn evoke the cortical activity profile of physiological sleep stages $[59,64]$. During sleep, these ascending transmitter systems modulate the activity of key component areas within the DMN $[12,13,64]$. The DMN includes the mesial temporal lobes and outflow projections to the posterior cingulate, to the medial and inferior parietal and prefrontal cortices and their subcortical connections $[7,12]$. The core function of the network continues to be defined, but it is active during stimulus-independent thought in the resting wakeful (and dreaming) brain [7, 59, 60]. Functional alterations in the DMN have been consistently identified in neuroimaging studies [6-8] of AD. Brainstem systems projecting to the DMN together with the DMN proper are likely to be integral to the development of $\mathrm{AD}$; brainstem nuclei (in particular, the locus coeruleus) and ascending neurotransmitter systems comprise the 'isodendritic core' or reticular formation [66] and are among the earliest targets of AD pathology [1].

Emerging evidence suggests a fundamental, functional linkage between the neurobiology of sleep and AD. Sleep, in particular rapid eye movement (REM) sleep, is postulated to have restorative effects on neuronal function [67] and may promote synaptic efficiency $[21,46]$. The role played by this process has recently been emphasised as a guiding principle of brain operation in a novel account of sleep neurobiology proposed by Hobson and Friston [46]. According to this account, ascending brainstem neurotransmitter systems interacting with components of the DMN are essential for maintaining and updating the brain's internal model of the world by minimising redundant complexity in synaptic networks. Such a generic sleep-related function would provide a mechanism linking increased time awake due to sleep deprivation with inefficient synaptic firing and increased vulnerability of neural networks hosting these dysfunctional synaptic connections. As a core projection target of the neurotransmitter pathways that mediate sleep-wake cycling, the DMN may be particularly susceptible to the effects of sleep disruption. Such selective susceptibility of the DMN is predicted by the hub vulnerability theory, according to which synaptic overactivity facilitates neurodegeneration $[21,43]$. Synaptic effects of sleep deprivation are unlikely to be restricted to a single pathophysiological mechanism; for example, synaptic overactivity, inefficient pruning or remodelling of redundant synapses and perturbed synaptic scaling and homeostasis might all operate within the DMN over different timescales and would be mutually reinforcing.

While sleep promotes complexity reduction and the regulation of redundant synaptic connections, ongoing involvement of the DMN in these processes during wakefulness is very likely on anatomical grounds. If correct, this account would therefore place the DMN and its modulation by sleep at the foreground of brain function across the circadian cycle both in health and in $\mathrm{AD}$. A disease state such as AD that initially damages sleep control mechanisms in the isodendritic core would have potentially widespread and cumulative effects on synaptic function in the core and its projection zones in the DMN [66]. In particular, if the dynamic toxic state generated within the network and the associated failure of synaptic 
Table 1. Key features, predictions and proposed tests of the hypnic hypothesis of AD

\begin{tabular}{|c|c|c|}
\hline Features & Predictions & Tests \\
\hline \multicolumn{3}{|l|}{ Systems level } \\
\hline $\begin{array}{l}\text { - Pathology in brainstem } \\
\text { pathways critical for } \\
\text { sleep-wake and circadian } \\
\text { physiology }\end{array}$ & $\begin{array}{l}\text { - Pathological changes in brainstem nuclei } \\
\text { implicated in circadian control } \\
\text { - Dysfunction and degeneration of } \\
\text { ascending neurotransmitter pathways } \\
\text { - Altered sleep/circadian physiology }\end{array}$ & 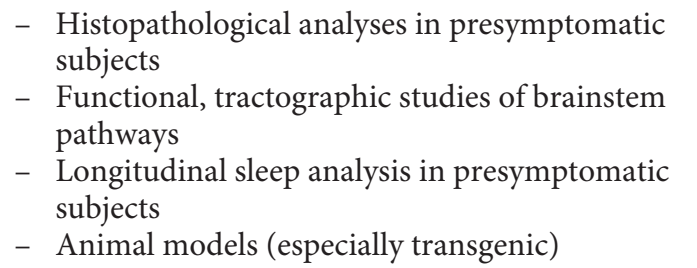 \\
\hline $\begin{array}{l}\text { - Sleep disruption drives } \\
\text { subsequent } \\
\text { neurodegeneration }\end{array}$ & $\begin{array}{l}\text { Disrupted sleep/circadian patterns early in } \\
\text { clinical course precedes cognitive decline, } \\
\text { cortical dysfunction and atrophy }\end{array}$ & $\begin{array}{l}\text { - Longitudinal sleep analyses in presymptomatic } \\
\text { subjects with parallel neuroimaging } \\
\text { - Early intervention to ameliorate sleep disruption } \\
\text { - Epidemiological studies assessing effects of } \\
\text { premorbid neuronal activity (e.g. occupation, } \\
\text { educational attainment) } \\
\text { - } \text { Animal models (especially transgenic) }\end{array}$ \\
\hline $\begin{array}{l}\text { - REM sleep is an active } \\
\text { 'rescue' state }\end{array}$ & $\begin{array}{l}\text { - REM deprivation and augmentation effects } \\
\text { on cognitive/neuronal function }\end{array}$ & $\begin{array}{l}\text { - Sleep analyses in AD subjects } \\
\text { - Animal models with selective REM deprivation }\end{array}$ \\
\hline $\begin{array}{l}\text { - Self-amplification of sleep } \\
\text { disruption effects }\end{array}$ & $\begin{array}{l}\text { - Neurodegeneration and sleep alteration } \\
\text { accelerating in tandem }\end{array}$ & $\begin{array}{l}\text { - Longitudinal sleep analyses, cognitive tests, } \\
\text { neuroimaging in AD subjects } \\
\text { - Sleep parameters manipulated in animal models }\end{array}$ \\
\hline $\begin{array}{l}\text { Cellular level } \\
\text { - Sleep disruption drives } \\
\text { pro-inflammatory and } \\
\text { oxidant states }\end{array}$ & $\begin{array}{l}\text { - Pro-inflammatory, pro-oxidant responses } \\
\text { correlated with circadian indices }\end{array}$ & $\begin{array}{l}\text { - Animal models with biochemical studies } \\
\text { - Human plasma studies }\end{array}$ \\
\hline \multicolumn{3}{|l|}{ Molecular level } \\
\hline $\begin{array}{l}\text { - Altered expression of cir- } \\
\text { cadian genes predisposes } \\
\text { to neurodegeneration }\end{array}$ & $\begin{array}{l}\text { - Altered expression profiles of (e.g. } \\
\text { circadian clock) gene effects on } \\
\text { neurodegeneration }\end{array}$ & $\begin{array}{l}\text { - Genomic, endophenotypic analyses } \\
\text { - Transgenic animal models }\end{array}$ \\
\hline $\begin{array}{l}\text { - AD-related genes produce } \\
\text { circadian alterations }\end{array}$ & $\begin{array}{l}\text { - Primary alterations in circadian indices in } \\
\text { at-risk individuals }\end{array}$ & - Sleep analyses in at-risk young subjects \\
\hline
\end{tabular}

repair lead to accumulation and transmission of pathogenic misfolded proteins, then neural damage would in time become self-amplifying and self-perpetuating (see fig. 1). [10, 21, 24].

We now consider the evidence for the hypothesis and its implications in more detail.

\section{Evidence for the Hypothesis: Sleep Alterations in AD}

A hypnic hypothesis of $\mathrm{AD}$ requires, firstly, that sleep disturbance should form part of the early clinical phenotype. Indeed, though difficult to study rigorously outside specialised sleep laboratories, substantial evidence sug- 


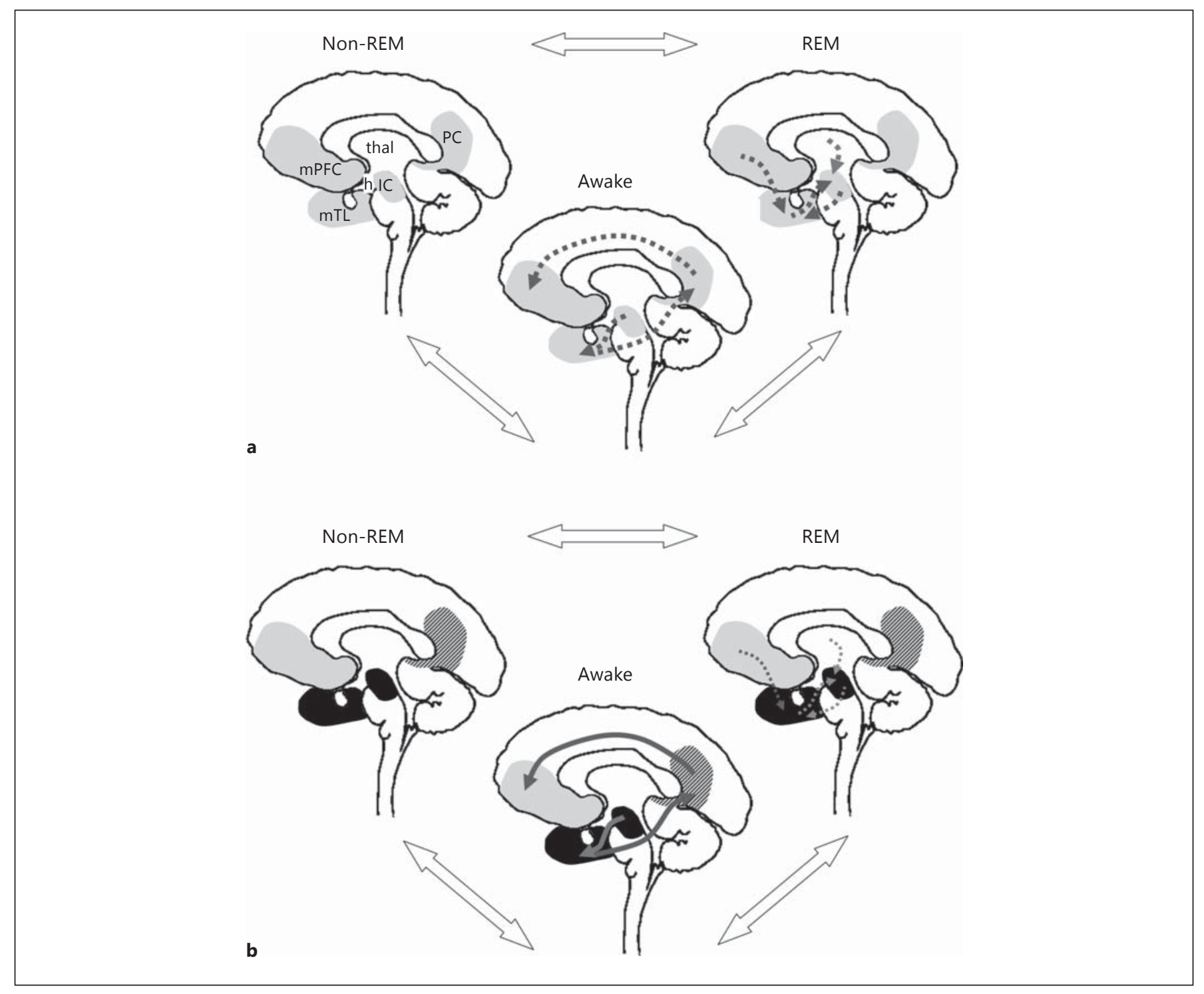

Fig. 1. A schematic representation of the hypnic hypothesis of $A D$ pathophysiology. The panels show non-sleep-deprived (a) and sleep-deprived (b) states. The circadian cycle is shown in simplified form comprising awake, REM sleep and non-REM sleep phases (state transitions shown as bidirectional, open arrows). The brain in each state is represented in a stylised mid-sagittal section. a Non-sleep-deprived state. Key components of the DMN and its subcortical projections implicated in $\mathrm{AD}$ are shown in grey; other areas playing a critical role in sleep physiology and linked to DMN are also shown. IC = Isodendritic core in the upper brainstem; $\mathrm{mTL}=$ medial temporal lobe $\mathrm{mPFC}=$ medial prefrontal cortex (here including anterior cingulate); $\mathrm{PC}=$ posterior cingulate/precuneus; $\mathrm{h}=$ hypothalamus; thal $=$ thalamus. According to the hypnic hypothesis of $\mathrm{AD}$, the non-sleep-deprived state is associated with an equilibrium between processes associated with increased synaptic activity that promote neurodegeneration during waking and counteractive processes during the relatively tonically quiescent phase of non-REM sleep and an active 'rescue' phase of synaptic remodelling associated with REM sleep. Cumulative syn- aptic dysfunction associated with waking directs pro-inflammatory and pro-fibrillogenic alterations in anatomically restricted projection zones in the DMN (dotted arrows); these alterations are actively opposed especially during REM sleep (reversed dotted arrows). $\mathbf{b}$ Sleep-deprived state. In this state the net balance of effects favours neurodegeneration, and repair processes associated with sleep phases are inefficient or attenuated, with consolidation of neuronal damage leading ultimately to chronic neuronal dysfunction (cross-hatched grey areas) and frank neuronal loss (black areas).The topography of brainstem projections and inter-linked $\mathrm{DMN}$ regions gives rise to a specific anatomical evolution of $\mathrm{AD}$ pathology targeting the DMN (solid grey arrows). AD itself induces sleep disruption due to early involvement of IC, leading to a toxic, self-amplifying and self-perpetuating state of chronic sleep disruption. Not shown explicitly in the figure is the spectrum of factors (including neurotransmitter and melatonin shifts and reactive oxygen and inflammatory intermediates) associated with sleep disruption that further amplify and perpetuate the neurodegenerative process (see text for details). 
gests that sleep-wake cycle disruption is a significant issue detectable in early $\mathrm{AD}$ and becomes more severe with disease evolution. It has been proposed that chronic sleep deprivation and associated neuronal overactivity may directly confer an increased risk of developing $\mathrm{AD}$ [26]. Sleep disturbance is more frequent in patients with $\mathrm{AD}$ than the general population [36], occurring in some $25-54 \%$ of patients overall $[54,58]$; as this is based largely on caregiver reports, it may be an underestimate. Sleep disturbance occurs early in the course of disease [61] and worsens as disease evolves [27, 69], though not necessarily in a simple monotonic relation $[39,63]$. Sleep disruption is an important determinant of institutionalisation in later-stage disease [42]. Normal ageing is associated with increased sleep latency and frequent night time awakenings [24] leading to increased daytime sleepiness [36, 37], features which are exaggerated in $\mathrm{AD}$ [39]. AD is associated with decreased slow-wave sleep and REM sleep, prolonged REM latency, increased proportions of stages I and II sleep, and increased fragmentation of sleep, leading to an overall decrease in sleep duration $[36,39]$. Even after accounting for the effects of increased sleep fragmentation, $\mathrm{AD}$ is also associated with shifts in the normal circadian alertness profile (contributing to 'sundowning' in later-stage disease) [3537], consistent with a specific impairment of circadian pacemaker function.

Very little information is currently available concerning dream morphology in AD. Nightmares can be a prominent feature of treatment with cholinesterase inhibitors, although the mechanism is debated $[70,71]$. Alteration in several sleep parameters correlates with measures of performance across cognitive domains in $\mathrm{AD}[37,39]$, suggesting a pervasive effect on cognitive function.

An obvious question in this situation is whether the correlation of increased cognitive dysfunction and sleep disruption in $\mathrm{AD}$ might simply reflect the known cognitive effects of sleep deprivation. This seems unlikely as the cognitive effects of sleep deprivation are attenuated during normal ageing [69], while the cognitive parameters linked to sleep disturbance in AD mirror the typical cognitive profile of the disease [37, 39]. More direct evidence linking sleep disturbance with subsequent neurodegeneration has been obtained in animal models; alterations of REM sleep and circadian architecture similar to those in human $\mathrm{AD}$ patients precede deposition of amyloid plaques in APP transgenic mice [25].

A Hypnic Hypothesis of AD

\section{Evidence for the Hypothesis: The Neurobiology of Sleep}

A second line of evidence linking sleep pathophysiology with development of $\mathrm{AD}$ pathology rests on the common involvement of brainstem neurotransmitter systems in these processes. The normal sleep-wake cycle is governed by the interaction of neurochemical (in particular, cholinergic and aminergic) systems in the upper brainstem, hypothalamus and basal forebrain and their subcortical and cortical projections. The cholinergic forebrain innervation originates mainly in the basal nucleus of Meynert and the noradrenergic innervation in the locus coeruleus [63]. Together with orexin released by the posterolateral hypothalamus, the ascending pathways diffusely promote wakefulness; GABA- and galanin-mediated inhibition of these pathways by the rostral hypothalamus triggers sleep onset, while mutual inhibition between pathways regulates transitions among sleep stages [68]. The circuitry mediating sleep-wake transitions is modulated by signals sent from the circadian pacemaker in the suprachiasmatic nucleus and by humoral factors (in particular, melatonin), allowing entrainment with environmental factors such as the day-night cycle [68]. The neuronal systems mediating the circadian cycle project to areas within the DMN $[63,66,72,73]$.

The stages of sleep and wakefulness have characteristic electrophysiological signatures, reflecting underlying thalamocortical activity patterns: non-REM sleep is associated with slow delta and 'spindle' activity due to oscillatory firing of thalamic neurons and synchronised cortical activity, while wakefulness and REM sleep are associated with thalamocortical desynchronisation $[46,64,68]$. Functionally, non-REM sleep is likely to be crucial for memory consolidation and synaptic regulation more generally [74], while REM sleep may serve to develop and maintain normal waking consciousness by building an internal predictive 'model' of the world that can then be tested and refined in response to waking sensory experience $[46,65]$. The noradrenergic locus coeruleus fires maximally during wakeful states, decreases its activity during non-REM sleep and is silent during REM sleep [68]. The serotonergic dorsal raphe nucleus also fires maximally during wakefulness and suppresses REM sleep [68]. Cholinergic neurons in the pons and basal forebrain fire during wakefulness and REM sleep [54]. Acting together via their specific effects on sleep stage transitions, multiple parallel ascending neurotransmitter systems modulate behavioural arousal, allowing programming of flexible motor and affective responses to the internal mi-

Neurodegener Dis 2013;12:165-176 
lieu and the external environment [68]. Endogenous circadian pacemaker effects on cognition and behaviour interact with (but are partly separable from) the effects of elapsed wakefulness and sleep periods per se [75]. This complex neurochemical milieu would also provide substrates to link sleep-wake alterations with mood alterations and $\mathrm{AD}[40,42]$.

In human functional neuroimaging studies, both nonREM and REM sleep are associated with complex, phasic, regionally specific profiles of cortical activity changes [51, 59]. Non-REM sleep is associated with tonic deactivation of brainstem, thalami, cingulate, mesial temporal and prefrontal areas; however, non-REM slow-wave activity is associated with increased activation of brainstem, ventral prefrontal, posterior cingulate/precuneus and parahippocampal areas $[51,59]$. Sleep spindles are associated with additional activation of thalamus, hippocampus, anterior cingulate and sensorimotor areas $[74,76]$. REM sleep is associated with activation of brainstem, thalami, anterior cingulate, mesial temporal and paralimbic areas and deactivation of posterior cingulate/precuneus, parietal and inferior frontal areas $[51,59,60,77]$. These activation profiles overlap extensively with the DMN, but also show that activity shifts are not uniform across the network [60]. Although the core function of the DMN remains controversial [78], it is known to mediate stimulus-independent thought during wakefulness. Activation of the DMN during REM sleep is therefore plausible a priori, since dreaming is arguably the purest example of stimulus-independent thought [46]. REM sleep is associated with specific alterations in DMN connectivity (in particular, reduced connectivity between posterior cingulate and more anterior regions) and reduced reactivity to sensory stimuli, which together may mediate REMspecific functions linked to 'isolation' of DMN subsystems from the external environment $[59,79]$.

Wakefulness tends to promote a net increase in synaptic strength, while sleep tends to attenuate synaptic strength $[20,80,81]$, which is consistent with the known restorative and homeostatic functions of sleep. However, these sleep functions are unlikely to reflect the net direction of activity shifts alone. For example, wakefulness and REM sleep are associated with similar metabolic profiles, suggesting that the quality (and not merely the overall amount) of synaptic activity mediates the restorative functions of the REM state. One potential expression of this qualitative alteration in synaptic drive may be a redistribution of connectivity between components of the DMN [79]. Although slow-wave (non-REM) sleep has generally been emphasised in synaptic homeostasis and downscal- ing of synaptic networks potentiated during wakefulness, recent evidence suggests that REM sleep plays an important role in these processes [47]. In particular, REM sleep is associated electrophysiologically with a specific profile of phasic synchrony shifts in hippocampal subregions [29], providing a substrate for altered network synchrony, synaptic plasticity and information transfer which may be regionally specific [52]. REM sleep deprivation in rats blocks expression of brain-derived neurotrophic factor [48], a key signalling molecule that modulates neural circuit activity and synaptic strength [18], while modafinil ameliorates the cognitive effects of REM deprivation in mice via increased expression of MMP-9, a gene implicated in synaptic plasticity [34]. We suggest that REM sleep may serve a crucial and active 'rescue' function in the repair of incipient neurodegenerative changes within synaptic circuits concentrated in the DMN.

REM sleep disruption early in the clinical course of $\mathrm{AD}$ is likely in part to result from degeneration of ascending cholinergic pathways, as these pathways are critical for initiating and maintaining REM sleep [54]. Chronic sleep deprivation in rats has been associated with the formation of anti-nerve growth factor antibodies [22] which, when infused into rat cerebral cortex, result in neurodegeneration of cortical cholinergic boutons [82], and transgenic anti-NGF mice develop Alzheimer-like neurodegeneration [83], suggesting a possible mechanism for sustained deleterious effects. The acetylcholinesterase inhibitor, donepezil, restores REM sleep in patients with mild-tomoderate $\mathrm{AD}$, and the magnitude of this effect correlates with cognitive benefit [41].

\section{Evidence for the Hypothesis: The Neuroanatomy of AD}

Our understanding of $\mathrm{AD}$ neurobiology has been transformed by a substantial body of neuroimaging data which demonstrates that the neurodegenerative process has a predictable and regionally specific evolution in the brain [1]. The very earliest disease targets in $\mathrm{AD}$ remain somewhat contentious but are likely to include entorhinal cortex and brainstem sites, including locus coeruleus, dorsal raphe nuclei or nucleus tractus solitarius $[2,8,84]$. Consistent with the early disruption of circadian and sleep physiology observed clinically, neuropathological evidence in AD clearly implicates ascending brainstem pathways that govern the sleep-wake cycle at or near the outset of the disease, including cholinergic, dopaminergic, melatoninergic and neurosteroid systems $[2,4,27,42$, 
$56,63] . \mathrm{AD}$ is a major cholinergic deficiency state [66], and cell loss in the nucleus basalis is correlated with the magnitude of cholinergic depletion in cerebral cortex [73]. In addition, neuronal counts in the locus coeruleus are reduced by some $80 \%$ in $\mathrm{AD}$ [57], with marked atrophy of the suprachiasmatic nucleus [67]. Involvement of the nucleus tractus solitarius could have particularly potent effects, as this area serves as a major 'signalling hub', integrating brainstem functions with the circadian pacemaker and widespread forebrain projection zones [84].

The forebrain projection targets of the ascending pathways disrupted in $\mathrm{AD}$ are widely distributed in the cerebral cortex, thalamus and other subcortical structures. However, there is a precise segregation of targets according to the specific transmitter systems involved [73]. For example, in the case of the cholinergic system, the hippocampus, amygdala and paralimbic structures receive particularly dense cholinergic innervation, and subregional variations in the strength of cholinergic inputs are evident within these structures. Furthermore, cholinergic projections to particular structures originate in distinct cholinergic neuronal pools in the brainstem and basal forebrain. This stratified organisation would support the mnestic functions mediated by the cholinergic system in the healthy brain and suggests a general mechanism for 'gating' sensory information to the limbic system [73]. In pathophysiological terms, such anatomical differentiation provides a potential substrate for the regionally directed spread of pathology in $\mathrm{AD}$, effectively 'focusing' the neurodegenerative process on vulnerable zones in the DMN and potentially establishing a gradient of regional vulnerability across the network (see fig. 1).

Early involvement of brainstem neurotransmitter systems may therefore explain the integral vulnerability of the $\mathrm{DMN}$ in $\mathrm{AD}[6,8,12,53]$. Neurotransmitter cycling is closely linked to neural activity [54], suggesting that altered patterns of neural activity in the DMN projection zones of damaged neurotransmitter pathways may govern the expression of AD. The evidence we have presented above demonstrates that sleep-wake cycling is a particularly potent example of large-scale alterations in neural activity focused in the DMN.

\section{Evidence for the Hypothesis: Cellular and Molecular Links between Sleep and Neurodegeneration}

Previous animal work has suggested that altered patterns of sleep-wake activity may directly promote neurodegenerative brain damage and these effects could oper- ate early in the pathophysiological cascade. Increased apoptosis, cytoskeletal disintegration and neuronal loss have been observed in the locus coeruleus of rat brain after REM sleep deprivation [44]. Neurons in the dorsal raphe nucleus may increase in size after REM sleep deprivation as a partial compensatory response to injury and (if not reversed) a potential prerequisite for neurodegeneration [44]. Cell size can be normalised by prazosin, suggesting that the response is mediated by noradrenergic pathways [44].

At a molecular level, potential links between sleep-related activity and substrates for neurodegenerative damage have been identified. Disrupted circadian function in mouse models with reduced expression of clock gene proteins (key regulators of circadian rhythm) is associated with accelerated ageing and impaired cognition via sleepdependent and sleep-independent effects [27]. Sleep duration has been shown to be linearly related to telomere length in men, suggesting that in human subjects chronic sleep deprivation may also accelerate ageing [85]. In rat cerebral cortex, chronic sleep deprivation has a unique molecular profile of gene upregulation compared with shorter-term sleep deprivation [22]. More specifically, genetic factors may link sleep disruption with the pathophysiology of $\mathrm{AD}$. While the effect of apolipoprotein $\mathrm{E}$ status has been inconsistent $[58,67]$, both increased susceptibility to sleep disturbance in $\mathrm{AD}$ [58] and overall risk of developing $\mathrm{AD}$ [86] have been linked to polymorphisms of the gene-coding monoamine oxidase $\mathrm{A}$, which helps govern the availability of serotonin in melatonin synthesis. This genetic factor also provides a potential link to mood disturbance, in line with evidence that depressive episodes can predict subsequent development of $\mathrm{AD}[40]$.

At a cellular and synaptic level, how might sleep disturbance promote $\mathrm{AD}$-associated pathophysiological alterations and, ultimately, neurodegeneration? Several general candidate mechanisms have been identified. These mechanisms interact and can be broadly considered as pro-inflammatory, pro-fibrillogenic and miscommunicative.

The changes in sleep circuitry and associated neurotransmitters in $\mathrm{AD}$ have pro-inflammatory effects. This pro-inflammatory state could have reciprocal pathogenic interactions with specific brainstem hub regions [84]. Sleep disruption is associated with dysregulation of the physiological stress response with altered secretion of cortisol and other neurosteroids, and these substances in turn modulate cholinergic functions [27, 42]. In addition, sleep disruption leads to reduced cellular tolerance of oxidation 
stress, which in turn is likely to reflect loss of neuroprotective functions, increased generation of reactive oxygen species, altered transduction of intracellular metabolic signals and reduced DNA repair [27, 87]. The outcome of this cascade is neuronal dysfunction and death. The cascade may be triggered by an $\mathrm{AD}$-associated reduction in the release of melatonin [50]. A pro-inflammatory mechanism of cell death may operate in various disease processes (it may, for example, account for the finding of accelerated hippocampal atrophy in obstructive sleep apnoea, perhaps mediated by phasic hypoxia) $[88,89]$. AD specificity would, however, emerge both in the initial sequence of cellular events that triggers the pro-inflammatory cascade and in the anatomical configuration of the pathways that are primarily damaged by the cascade (see fig. 1 ).

Sleep disruption in AD is likely to promote deposition of pathogenic fibrillar proteins. Synaptic activity has been shown using in vivo microdialysis to regulate levels of $\beta$-amyloid in interstitial fluid [45]. More specifically, in transgenic APP mice, sleep deprivation is associated with increased levels of interstitial fluid $\beta$-amyloid and, subsequently, increased deposition of amyloid plaques, while sleep induction with an orexin antagonist decreases plaque burden relative to control mice [26]. In human subjects, the diurnal level of $\beta$-amyloid-42 (the soluble oligomeric species implicated in generating amyloid plaques) in cerebrospinal fluid (CSF) is increased by wakefulness and decreased by sleep [24], while the level of $\beta$-amyloid in interstitial fluid is regulated by endogenous neuronal activity (as indexed by lactate production) [45]. Manipulation of synaptic vesicle release affects $\beta$-amyloid levels in interstitial fluid, suggesting a direct mechanistic link [45]. Conversely, both the diurnal fluctuation of CSF $\beta$-amyloid levels and the sleep-wake cycle can be normalised by immunisation against $\beta$-amyloid- 42 in transgenic mouse models of $\mathrm{AD}$ [33]. Melatonin has anti-fibrillary actions [31] and inhibits deposition of $\beta$-amyloid and development of cognitive deficits in mouse models of $\mathrm{AD}[23,27,28]$. Although clinical trials of melatonin have had somewhat mixed results [90-92], there is some evidence that it can delay deposition of $\beta$-amyloid in mouse models, improve survival in mouse models of $\mathrm{AD}$ [28], and improve cognition in patients with mild cognitive impairment [38]. Effects of sleep-wake alterations on pathogenic protein deposition are not restricted to $\beta$-amyloid. A similar link has been demonstrated for protein tau, the other major culprit protein implicated in $\mathrm{AD}$ pathogenesis. In mice, tau content is increased in the pons, preoptic area and hippocampus after $24 \mathrm{~h}$ of REM sleep deprivation and in the frontal cortex after $72 \mathrm{~h}$ of
REM sleep deprivation [32]. These findings suggest that sleep disruption may lead to tissue-specific alteration in the neural cytoskeleton associated with protein tau deposition. In murine models of sleep deprivation there is evidence of an adaptive response to accumulated misfolded proteins which involves upregulation of unfolded protein response mechanisms in the endoplasmic reticulum. This adaptive response is impaired in aged mice, leading to accumulation of misfolded proteins and accelerating the proapoptotic cascade [30].

A further possible mechanism that could link sleep disruption to neurodegeneration is alteration in the pattern of synaptic activity, leading to neuronal miscommunication [10]. This is presently the least well worked out of the candidate mechanisms we consider, but might potentially precede and instigate pro-inflammatory and pro-fibrillary cascades. Furthermore, it provides a potential modus operandi for the trans-synaptic spread of pathology across the vulnerable network, an emerging principle that is likely to be relevant to the evolution of a range of neurodegenerative diseases [9]. We propose that neuronal miscommunication across synapses may be the fundamental mechanism underpinning the hypnic hypothesis of $\mathrm{AD}$, leading processes of frank degeneration. Cellular miscommunication need not be restricted to neurons; it might also blight neuronal-glial interactions [10]. Abnormal or inefficient synaptic activity could restrict delivery of trophic factors or promote intercellular transfer of misfolded pathogenic proteins [10]. Diffusive or 'prion-like' spread of pathogenic proteins has been demonstrated in animal models for both $\beta$-amyloid [16] and tau [15]. In addition, altered synaptic activity might itself promote local protein misfolding in the presence of pre-toxic substrates (e.g. enhanced tau phosphorylation via increased nerve growth factor release [4]) or might exert less specific excitotoxic effects (e.g. by triggering the pro-inflammatory cascade). Once present, pathogenic proteins may furtherdegrade synapticfunction. For example, $\beta$-amyloid fragments may alter synaptic transmission via an AMPAmediated glutamatergic mechanism [93], while tau modulates the synchronous firing of neurones [94].

The mechanisms we have considered would have many potential points of convergence and amplification (see fig. 1). For example, melatonin, in addition to its neuroprotective and anti-fibrillary effects, enhances cholinergic function [95]. Melatonin deficiency would therefore tend to promote abnormal activity at cholinergic synapses. Increased neuronal activity may promote accumulation of $\beta$-amyloid [7], while deposition of $\beta$-amyloid in turn disrupts synaptic function $[6,96]$. The pro-inflam- 
matory cascade may reduce clearance of pathogenic proteins, thereby accelerating fibrillary transformation, and may also inhibit synaptic repair [10]. Once the neurodegenerative process in $\mathrm{AD}$ becomes established, the prooxidant state would be perpetuated by the deposition of amyloid plaques and neurofibrillary tangles. Pathogenic proteins may act to consolidate and perpetuate the abnormal toxic state (e.g. protein tau itself may indirectly regulate the sleep-wake cycle) [94].

\section{Testing the Hypothesis}

We propose this hypnic hypothesis of AD with caveats. Despite recent progress, our understanding of sleep neurobiology and $\mathrm{AD}$ pathophysiology remains limited. In particular, the mechanisms that link molecular and cellular events to neural circuit damage remain to be established in detail. We do not, of course, propose that sleep disturbance is the sole factor driving the development of $\mathrm{AD}$ - rather, we envisage it as a key factor in consolidating and amplifying the neurodegenerative process in core vulnerable brain areas. Taking these caveats into account, the hypnic hypothesis makes certain specific predictions with potentially far-reaching implications that might be tested in future work (summarised in table 1). The hypothesis implies, for example, that chronic sleep disruption might promote the development of $\mathrm{AD}$ and, conversely, that appropriate treatment to regularise sleep patterns, in particular to augment REM sleep, might prevent (or at least retard) its development. Arguably, any hypnic effect might be relatively more important early in the evolution if $\mathrm{AD}$, before the neurodegenerative process is fully established and secondary pathogenic mechanisms have come into play. Aside from its importance in establishing the pathophysiological sequence, early-stage disease is a more feasible candidate for detailed polysomnographic studies than established dementia.

Perhaps the most basic requirement will be a detailed, prospective longitudinal analysis to track sleep physiology in relation to early markers of disease onset (ideally, predating the development of cognitive decline). This would be logistically challenging but could be directed to cohorts at known risk of developing $\mathrm{AD}$ (e.g. carriers of disease-causing mutations), capitalising on recent progress in identifying novel biomarkers of $\mathrm{AD}$ such as CSF tau, $\beta$-amyloid assays and amyloid brain imaging, as well as laboratory markers of circadian function (such as melatonin). There is a particular need to investigate REM sleep and dreaming in $\mathrm{AD}$, about which information re- mains very limited. Complementary approaches should include large-scale clinical epidemiological studies to assess relative AD risk associated with habitual sleep patterns (e.g. those associated with particular occupations) and, potentially, therapeutic trials of sleep-regularising agents, if these can be administered sufficiently early in the course of disease. Ultimately, detailed pathological correlation will be required in individuals with $\mathrm{AD}$ undergoing comprehensive assessment of sleep physiology during life.

More fundamentally, the pathophysiology of sleep remains to be worked out in detail at cellular and circuit levels. This will entail the development of animal and in vitro models that can capture the effects of $\mathrm{AD}$ pathology, the effects of perturbed cellular interactions on the spread of AD pathology in model neural circuits, and compensatory cellular and synaptic responses. Animal models also allow evaluation of the impact of specific manipulations of sleep physiology (e.g. selective REM deprivation or augmentation) on molecular and behavioural phenotypes. In addition, more information is needed about early markers of DMN pathophysiology. This might entail, for example, an analysis of complex behavioural alterations (potentially expressed in social, affective or mood changes) that are not conventionally regarded as part of the typical phenotype of established AD but which may well go under-recognised [40]. Animal models are potentially particularly valuable for charting the evolution of circadian disturbances in relation to neurodegenerative pathology and the effects of interventions [25].

Finally, we speculate that the hypnic hypothesis of $\mathrm{AD}$ might exemplify a much broader class of disease mechanisms, namely, neurodegeneration instigated by abnormal neural network behaviour. Sleep illustrates a gross and pervasive alteration in brain function. It remains to be established whether more subtle, habitual patterns of brain activity might promote other kinds of pathophysiological deterioration. Examples might include the cognitive patterns associated with certain occupations, which have been associated epidemiologically with particular neurodegenerative syndromes [97], or the role of educational attainment [54]. Consistent with this notion, sensorially enriched environments have been shown to affect the development of the neurodegenerative process (as indexed by rates of deposition of amyloid plaques) in animal models of AD [98-100]. These effects may be mediated in part by exercise-associated influences on cholinergic activity and neuronal plasticity [101]. If we are to explain the syndromic specificity of particular neurodegenerative pa- 
thologies, it is critical that we uncover the processes that link molecular lesions to large-scale network disintegration [9]. The functional properties of neural circuits and their modes of operation in generating complex (including circadian) behaviours are a largely unexplored but potentially critical link by which cellular events might imprint and propagate themselves across vulnerable networks at the level of the whole brain. The creation of programmable neural networks in vivo offers the exciting prospect of assessing such processes directly [102].

\section{Acknowledgements}

We thank Professors Martin Rossor and Nick Fox for helpful discussion and our anonymous reviewers for constructive suggestions. This work was undertaken at UCLH/UCL, which received a proportion of funding from the Department of Health's NIHR Biomedical Research Centres funding scheme. The Dementia Research Centre is an Alzheimer's Research UK Co-ordinating Centre. This work was also funded by the Medical Research Council UK and by the Wellcome Trust. J.D.W. is supported by a Wellcome Trust Senior Clinical Fellowship (grant No. 091673/Z/10/Z).

\section{References}

1 Braak H, Braak E: Neuropathological stageing of Alzheimer-related changes. Acta Neuropathol 1991;82:239-259.

- 2 Braak H, Del Tredici K: The pathological process underlying Alzheimer's disease in individuals under thirty. Acta Neuropathol 2011; 121:171-181.

-3 Fontejin HM, Modat M, Clarkson MJ, Barnes J, Lehmann M, Hobbs NZ, Scahill RI, Tabrizi SJ, Ourselin S, Fox NC, Alexander DC: An event-based model for disease progression and its application in familial Alzheimer's disease and Huntington's disease. Neuroimage 2012;60:1880-1889.

4 Schliebs R, Arendt T: The cholinergic system in aging and neuronal degeneration. Behav Brain Res 2011;221:555-563.

5 Sperling RA, Aisen PS, Beckett LA, Bennett DA, Craft S, Fagan AM, Iwatsubo T, Jack CR Jr, Kaye J, Montine TJ, Park DC, Reiman EM, Rowe CC, Siemers E, Stern Y, Yaffe K, Carrillo MC, Thies B, Morrison-Bogorad M, Wagster MV, Phelps CH: Toward defining preclinical stages of Alzheimer's disease: recommendations from the National Institute on Aging - Alzheimer's Association workgroups on diagnostic guidelines for $\mathrm{Al}$ zheimer's disease. Alzheimers Dement 2011; 7:280-292.

6 Buckner RL, Snyder AZ, Shannon BJ, La Rossa G, Sachs R, Fotenos AF, Sheline YI, Klunk WE, Mathis CA, Morris JC, Mintun MA: Molecular, structural and functional characterisation of Alzheimer's disease: evidence for a relationship between default activity, amyloid and memory. J Neurosci 2005;25:7709-7717.

-7 Buckner RL, Andrews-Hanna JR, Schacter DL: The brain's default network: anatomy, function, and relevance to disease: Ann NY Acad Sci 2008;1124:1-38.

8 Pievani M, de Haan W, Wu T, Seeley WW, Frisoni GB: Functional network disruption in the degenerative dementias. Lancet Neurol 2011;10:829-843.

-9 Warren JD, Rohrer JD, Hardy J: Disintegrating brain networks from syndromes to molecular nexopathies. Neuron 2012;73:10601062.
10 Garden GA, La Spada AR: Intercellular (mis) communication in neurodegenerative disease. Neuron 2012;73:886-901.

11 Crews L, Masliah E: Molecular mechanisms of neurodegeneration in Alzheimer's disease. Hum Mol Genet 2010;19:R12-R20.

12 Raichle ME, MacLeod AM, Snyder AZ, Powers WJ, Gusnard DA, Shulman GL: A default mode of brain function. Proc Natl Acad Sci USA 2001;98:676-682.

13 Cavanna AE, Trimble MR: The precuneus: a review of its functional anatomy and behavioural correlates. Brain 2006;129:564-583.

$\checkmark 14$ De Calignon A, Polydoro M, Suárez-Calvet M, William C, Adamowicz DH, Kopeikina KJ, Pitstick R, Sahara N, Ashe KH, Carlson GA, Spires-Jones TL, Hyman BT: Propagation of tau pathology in a model of early Alzheimer's disease. Neuron 2012;73:685-697.

15 Liu L, Drouet V, Wu JW, Witter MP, Small SA, Clelland C, Duff K: Trans-synaptic spread of tau pathology in vivo. PLoS One 2012; 7:e31302.

16 Harris JA, Devidze N, Verret L, Ho K, Halabisky B, Thwin MT, Kim D, Hamto P, Lo I, Yu GQ, Palop JJ, Masliah E, Mucke L: Transsynaptic progression of amyloid- $\beta$-induced neuronal dysfunction within the entorhinalhippocampal network. Neuron 2010;68:428441.

17 Nizzari M, Thellung S, Corsaro A, Villa V, Pagano A, Porcile C, Russo C, Florio T: Neurodegeneration in Alzheimer disease: role of amyloid precursor protein and presenilin 1 intracellular signaling. J Toxicol 2012;2012: 187297.

18 Bachmann V, Klein C, Bodenmann S, Schäfer N, Berger W, Brugger P, Landolt HP: The BDNF Val66Met polymorphism modulates sleep intensity: EEG frequency and state specificity. Sleep 2012;35:335-344.

19 Hanlon EC, Vyazovskiy VV, Faraguna U, Tononi G, Cirelli C: Synaptic potentiation and sleep need: clues from molecular and electrophysiological studies. Curr Top Med Chem 2011;11:2472-2482.

20 Vyazovskiy VV, Cirelli C, Pfister-Genskow M, Faraguna U, Tononi G: Molecular and electrophysiological evidence for net synaptic potentiation in wake and depression in sleep. Nat Neurosci 2008;11:200-208.

21 Bero AW, Yan P, Roh JH, Cirrito JR, Stewart FR, Raichle ME, Lee JM, Holtzman DM: Neuronal activity regulates the regional vulnerability to amyloid- $\beta$ deposition. Nat Neurosci 2011;14:750-756.

22 Cirelli C: Cellular consequences of sleep deprivation in the brain. Sleep Med Rev 2006; 10: 307-321.

23 Feng Z, Chang Y, Cheng Y, Zhang BL, Qu ZW, Qin C, Zhang JT: Melatonin alleviates behavioral deficits associated with apoptosis and cholinergic system dysfunction in the APP 695 transgenic mouse model of Alzheimer's disease. J Pineal Res 2004;37:129-136.

24 Huang Y, Potter R, Sigurdson W, Santacruz A, Shih S, Ju YE, Kasten T, Morris JC, Mintun M, Duntley S, Bateman RJ: Effects of age and amyloid deposition on $A \beta$ dynamics in the human central nervous system. Arch Neurol 2012;69:51-58.

25 Huitrón-Reséndiz S, Sánchez-Alavez M, Gallegos R, Berg G, Crawford E, Giacchino JL, Games D, Henriksen SJ, Criado JR: Age-independent and age-related deficits in visuospatial learning, sleep-wake states, thermoregulation and motor activity in PDAPP mice. Brain Res 2002;928:126-137.

26 Kang JE, Lim MM, Bateman RJ, Lee JJ, Smyth LP, Cirrito JR, Fujiki N, Nishino S, Holtzman DM: Amyloid- $\beta$ dynamics are regulated by orexin and the sleep-wake cycle. Science 2009; 326:1005-1007.

27 Kondratova AA, Kondratov RV: The circadian clock and pathology of the ageing brain. Nat Rev Neurosci 2012;13:325-335.

28 Matsubara E, Bryant-Thomas T, Pacheco Quinto J, Henry TL, Poeggeler B, Herbert D, Cruz-Sanchez F, Chyan YJ, Smith MA, Perry G, Shoji M, Abe K, Leone A, Grundke-Ikbal I, Wilson GL, Ghiso J, Williams C, Refolo LM, Pappolla MA, Chain DG, Neria E: Melatonin increases survival and inhibits oxidative and amyloid pathology in a transgenic model of Alzheimer's disease. J Neurochem 2003;85: 1101-1108. 
29 Montgomery SM, Sirota A, Buzsáki G: Theta and gamma coordination of hippocampal networks during waking and rapid eye movement sleep. J Neurosci 2008;28:6731-6741.

-30 Naidoo N, Ferber M, Master M, Zhu Y, Pack AI: Aging impairs the unfolded protein response to sleep deprivation and leads to proapoptotic signaling. J Neurosci 2008;28:65396548.

-31 Poeggeler B, Miravalle L, Zagorski MG, Wisniewski T, Chyan YJ, Zhang Y, Shao H, Bryant-Thomas T, Vidal R, Frangione B, Ghiso J, Pappolla MA: Melatonin reverses the profibrillogenic activity of apolipoprotein $\mathrm{E} 4$ on the Alzheimer amyloid $\mathrm{A} \beta$ peptide. Biochemistry 2001;40:14995-15001.

- 32 Rodríguez-Vázquez J, Camacho-Arroyo I, Velázquez-Moctezuma J: Differential impact of REM sleep deprivation on cytoskeletal proteins of brain regions involved in sleep regulation. Neuropsychobiology 2012 65:161-167.

- 33 Roh JH, Huang Y, Bero AW, Kasten T, Stewart FR, Bateman RJ, Holtzman DM: Disruption of the sleep-wake cycle and diurnal fluctuation of $\beta$-amyloid in mice with Alzheimer's disease pathology. Sci Transl Med 2012;4: 150ra122.

- $34 \mathrm{He}$ B, Peng H, Zhao Y, Zhou H, Zhao Z: Modafinil treatment prevents REM sleep deprivation-induced brain function impairment by increasing MMP-9 expression. Brain Res 2011;1426:38-42.

-35 Bachman D, Rabins P: 'Sundowning' and other temporally associated agitation states in dementia patients. Annu Rev Med 2006;57:499_ 511.

36 Bombois S, Derambure P, Pasquier F, Monaca C: Sleep disorders in aging and dementia. J Nutr Health Aging 2010;14:212-217.

- 37 Bonanni E, Maestri M, Tognoni G, Fabbrini M, Nucciarone B, Manca ML, Gori S, Iudice A, Murri L: Daytime sleepiness in mild and moderate Alzheimer's disease and its relationship with cognitive impairment. J Sleep Res 2005;14:311-317.

38 Furio AM, Brusco LI, Cardinali DP: Possible therapeutic value of melatonin in mild cognitive impairment: a retrospective study. J Pineal Res 2007;43:404-409.

-39 Moe KE, Vitiello MV, Larsen LH, Prinz PN: Symposium: cognitive processes and sleep disturbances: sleep/wake patterns in $\mathrm{Al}$ zheimer's disease: relationships with cognition and function. J Sleep Res 1995;4:15-20.

-40 Vilalta-Franch J, López-Pousa S, Llinàs-Reglà J, Calvó-Perxas L, Merino-Aguado J, GarreOlmo J: Depression subtypes and 5-year risk of dementia and Alzheimer disease in patients aged 70 years. Int J Geriatr Psychiatry 2013; 28:341-350.

41 Wdos MS, Poyares DR, Guilleminault C, Ramos LR, Bertolucci PH, Tufik S: The effect of donepezil on sleep and REM sleep EEG in patients with Alzheimer disease: a double-blind placebo-controlled study. Sleep 2006;29:199_ 205.
42 Wulff K, Gatti S, Wettstein JG, Foster RG: Sleep and circadian rhythm disruption in psychiatric and neurodegenerative disease. Nat Rev Neurosci 2010;11:589-599.

43 De Haan W, Mott K, van Straaten EC, Scheltens P, Stam CJ: Activity-dependent degeneration explains hub vulnerability in $\mathrm{Al}$ zheimer's disease. PLoS Comput Biol 2012; 8:e1002582.

44 Ranjan A, Biswas S, Mallick BN: Cytomorphometric changes in the dorsal raphe neurons after rapid eye movement sleep deprivation are mediated by noradrenalin in rats. Behav Brain Funct 2010;6:62.

45 Cirrito JR, Yamada KA, Finn MB, Sloviter RS, Bales KR, May PC, Schoepp DD, Paul SM, Mennerick S, Holtzman DM: Synaptic activity regulates interstitial fluid amyloid- $\beta$ levels in vivo. Neuron 2005;48:913-922.

46 Hobson JA, Friston KJ: Waking and dreaming consciousness: neurobiological and functional considerations. Prog Neurobiol 2012;98: 82-98.

47 Born J, Feld GB: Sleep to upscale, sleep to downscale: balancing homeostasis and plasticity. Neuron 2012;75:933-935.

48 Shaffery JP, Lopez J, Roffwarg HP: Brain-derived neurotrophic factor (BDNF) reverses the effects of rapid eye movement sleep deprivation (REMSD) on developmentally regulated, long-term potentiation (LTP) in visual cortex slices. Neurosci Lett 2012;153:84-88.

- 49 Vyazovskiy VV, Cirelli C, Pfister-Genskow M, Faraguna U, Tononi G: Molecular and electrophysiological evidence for net synaptic potentiation in wake and depression in sleep. Nat Neurosci 2008;11:200-208.

50 Zhou JN, Liu RY, Kamphorst W, Hofman MA, Swaab DF: Early neuropathological Alzheimer's changes in aged individuals are accompanied by decreased cerebrospinal fluid melatonin levels. J Pineal Res 2003;35:125130 .

51 Jedidi Z, Rikir E, Muto V, Mascetti L, Kussé C, Foret A, Shaffii-Le Bourdiec A, Vandewalle G, Maquet $P$ : Functional neuroimaging of the reciprocal influences between sleep and wakefulness. Pflugers Arch 2012;463:103-109.

52 Grosmark AD, Mizuseki K, Pastalkova E, Diba K, Buzsáki G: REM sleep reorganizes hippocampal excitability. Neuron 2012;75: 1001-1007.

53 Scahill RI, Schott JM, Stevens JM, Rossor MN Fox NC: Mapping the evolution of regional atrophy in Alzheimer's disease: unbiased analysis of fluid-registered serial MRI. Proc Natl Acad Sci USA 2002;99:4703-4707.

54 Bero AW, Yan P, Roh JH, Cirrito JR, Stewart FR, Raichle ME, Lee JM, Holtzman DM: Neuronal activity regulates the regional vulnerability to amyloid- $\beta$ deposition. Nat Neurosci 2011;14:750-756.

55 Avidan AY: Sleep in the geriatric patient population. Semin Neurol 2005;25:52-63.

56 Benarroch EE: Suprachiasmatic nucleus and melatonin: reciprocal interactions and clinical correlations. Neurology 2008;71:594-598.
7 Bondareff W, Mountjoy CQ, Roth M: Loss of neurons of origin of the adrenergic projection to cerebral cortex (nucleus locus ceruleus) in senile dementia. Neurology 1982;32:164-168.

58 Craig D, Hart DJ, Passmore AP: Genetically increased risk of sleep disruption in Alzheimer's disease. Sleep 2006;29:1003-1007.

-59 Dang-Vu TT, Schabus M, Desseilles M, Sterpenich V, Bonjean M, Maquet P: Functional neuroimaging insights into the physiology of human sleep. Sleep 2010;33:1589-1603.

60 Domhoff WG: The neural substrate for dreaming: is it a subsystem of the default network? Conscious Cogn 2011;20:1163-1174.

61 Guarnieri B, Adorni F, Musicco M, Appollonio I, Bonanni E, Caffarra P, Caltagirone C, Cerroni G, Concari L, Cosentino FI, Ferrara S, Fermi S, Ferri R, Gelosa G, Lombardi G Mazzei D, Mearelli S, Morrone E, Murri L, Nobili FM, Passero S, Perri R, Rocchi R, Sucapane P, Tognoni G, Zabberoni S, Sorbi S: Prevalence of sleep disturbances in mild cognitive impairment and dementing disorders: a multicenter Italian clinical cross sectional study on 431 patients. Dement Geriatr Cogn Disord 2012;33:50-58.

62 Gabelle A, Dauvilliers Y: Editorial: sleep and dementia. J Nutr Health Aging 2010;14:201202

63 George O, Vallée M, Le Moal M, Mayo W: Neurosteroids and cholinergic systems: implications for sleep and cognitive processes and potential role of age-related changes. Psychopharmacology (Berl) 2006;186:402-413.

64 Hobson JA, Pace-Schott EF: The cognitive neuroscience of sleep: neuronal systems, consciousness and learning. Nat Rev Neurosci 2002;3:679-693.

65 Hobson JA: REM sleep and dreaming: towards a theory of protoconsciousness. Nat Rev Neurosci 2009; 10:803-813.

66 Rossor MN: Parkinson's disease and Alzheimer's disease as disorders of the isodendritic core. Br Med J (Clin Res Ed) 1981;283: $1588-1590$

-67 Yesavage JA, Friedman L, Kraemer H, Tinklenberg JR, Salehi A, Noda A, Taylor JL, O'Hara R, Murphy G: Sleep/wake disruption in Alzheimer's disease: APOE4 status and longitudinal course. J Geriatr Psychiatry Neurol 2004; 17:20-24.

68 España RA, Scammell TE: Sleep neurobiology from a clinical perspective. Sleep 2011;34: 845-858.

69 Pace-Schott EF, Spencer RM: Age-related changes in the cognitive function of sleep. Prog Brain Res 2011;191:75-89.

70 McCurry SM, Reynolds CF, Ancoli-Israel S, Teri L, Vitiello MV: Treatment of sleep disturbance in Alzheimer's disease. Sleep Med Rev 2000;4:603-628.

-71 Singer M, Romero B, Koenig E, Förstl H, Brunner H: Nightmares in patients with Alzheimer's disease caused by donepezil. Therapeutic effect depends on the time of intake (in German). Nervenarzt 2005;76: 1127-1129. 
72 Laxton AW, Tang-Wai DF, McAndrews MP, Zumsteg D, Wennberg R, Keren R, Wherrett J, Naglie G, Hamani C, Smith GS, Lozano AM: A phase I trial of deep brain stimulation of memory circuits in Alzheimer's disease. Ann Neurol 2010;68:521-534.

73 Mesulam MM: Structure and function of cholinergic pathways in the cerebral cortex, limbic system, basal ganglia, and thalamus of the human brain; in Bloom FE, Kupfer DJ (eds): Psychopharmacology: The Fourth Generation of Progress. New York, Raven Press, 1995, pp 135-146.

-74 Mascetti L, Foret A, Bourdiec AS, Muto V, Kussé C, Jaspar M, Matarazzo L, Dang-Vu T, Schabus M, Maquet P: Spontaneous neural activity during human non-rapid eye movement sleep. Prog Brain Res 2011;193:111118.

75 Wyatt JK, Ritz-De Cecco A, Czeisler CA, and Dijk DJ: Circadian temperature and melatonin rhythms, sleep, and neurobehavioral function in humans living on a 20-hour day. Am J Physiol 1999;277:R1152-R1163.

-76 Maquet P: Understanding non rapid eye movement sleep through neuroimaging. World J Biol Psychiatry 2010;11:9-15.

77 Desseilles M, Dang-Vu TT, Sterpenich V, Schwartz S: Cognitive and emotional processes during dreaming: a neuroimaging view. Conscious Cogn 2011;20:998-1008.

-78 Spreng RN, Mar RA, Kim AS: The common neural basis of autobiographical memory, prospection, navigation, theory of mind, and the default mode: a quantitative meta-analysis. J Cogn Neurosci 2009;21:489-510.

79 Koike T, Kan S, Misaki M, Miyauchi S: Connectivity pattern changes in default-mode network with deep non-REM and REM sleep. Neuroimage 2011;69:322-330.

80 Donlea JM, Ramanan N, Shaw PJ: Use-dependent plasticity in clock neurons regulates sleep need in Drosophila. Science 2009;324: 105-108.

81 Gilestro GF, Tononi G, Cirelli C: Widespread changes in synaptic markers as a function of sleep and wakefulness in Drosophila. Science 2009;324:109-112.
Debeir T, Saragovi HU, Cuello AC: A nerve growth factor mimetic TrkA antagonist causes withdrawal of cortical cholinergic boutons in the adult rat. Proc Natl Acad Sci USA 1999;96:4067-4072.

83 Capsoni S, Ugolini G, Comparini A, Ruberti F, Berardi N, Cattaneo A: Alzheimer-like neurodegeneration in aged antinerve growth factor transgenic mice. Proc Natl Acad Sci USA 2000;97:6826-6831.

84 Daulatzai MA: Dysfunctional nucleus tractus solitarius: its crucial role in promoting neuropathogenetic cascade of Alzheimer's dementia - a novel hypothesis. Neurochem Res 2012;37:846-868.

85 Jackowska M, Hamer M, Carvalho LA, Erusalimsky JD, Butcher L, Steptoe A: Short sleep duration is associated with shorter telomere length in healthy men: findings from the Whitehall II Cohort Study. PLoS One 2012; 7:e47292.

86 Oliveira JR, Nishimura AL, Lemos RR, Zatz $\mathrm{M}$ : The genetics of Alzheimer's disease in Brazil: 10 years of analysis in a unique population. J Mol Neurosci 2009;37:74-79.

87 Zhang J, Veasey S: Making sense of oxidative stress in obstructive sleep apnea: mediator or distractor? Front Neurol 2012;3:179.

88 Morrell MJ, Twigg G: Neural consequences of sleep disordered breathing: the role of intermittent hypoxia. Adv Exp Med Biol 2006;588: $75-88$.

89 Lim DC, Veasey SC: Neural Injury in sleep apnea. Curr Neurol Neurosci Rep 2010;10: 47-52.

-90 Singer C, Tractenberg RE, Kaye J, Schafer K, Gamst A, Grundman M, Thomas R, Thal LJ: A multicenter, placebo-controlled trial of melatonin for sleep disturbance in Alzheimer's disease. Sleep 2003;26:893-901.

91 Gehrman PR, Connor DJ, Martin JL, Shochat T, Corey-Bloom J, Ancoli-Israel S: Melatonin fails to improve sleep or agitation in doubleblind randomized placebo-controlled trial of institutionalized patients with Alzheimer disease. Am J Geriatr Psychiatry 2009;17:166169.

92 Serfaty M, Kennell-Webb S, Warner J, Blizard $R$, Raven P: Double-blind randomised placebo-controlled trial of low-dose melatonin for sleep disorders in dementia. Int J Geriatr Psychiatry 2002;17:1120-1127.
93 Hartell NA, Suh YH: Peptide fragments of $\beta$-amyloid precursor protein: effects on parallel fiber-Purkinje cell synaptic transmission in rat cerebellum. J Neurochem 2000; 74:1112-1121.

94 Cantero JL, Hita-Yañez E, Moreno-Lopez B, Portillo F, Rubio A, Avila J: Tau protein role in sleep-wake cycle. J Alzheimers Dis 2010; 21:411-421.

95 Wang JZ, Wang ZF: Role of melatonin in Alzheimer-like neurodegeneration. Acta Pharmacol Sin 2006;27:41-49.

96 Hernandez CM, Dineley KT: a7 nicotinic acetylcholine receptors in Alzheimer's disease: neuroprotective, neurotrophic or both? Curr Drug Targets 2012;13:613-622.

97 Spreng RN, Rosen HJ, Strother S, Chow TW, Diehl-Schmid J, Freedman M, Graff-Radford NR, Hodges JR, Lipton AM, Mendez MF, Morelli SA, Black SE, Miller BL, Levine B: Occupation attributes relate to location of atrophy in frontotemporal lobar degeneration. Neuropsychologia 2010;48:3634-3641.

-98 Lazarov O, Robinson J, Tang YP, Hairston IS, Korade-Mirnics Z, Lee VM, Hersh LB, Sapolsky RM, Mirnics K, Sisodia SS: Environmental enrichment reduces $A \beta$ levels and amyloid deposition in transgenic mice. Cell 2005;120:701-713.

99 Adlard PA, Perreau VM, Pop V, Cotman CW: Voluntary exercise decreases amyloid load in a transgenic model of Alzheimer's disease. J Neurosci 2005;25:4217-4221.

100 Jankowsky JL, Xu G, Fromholt D, Gonzales V, Borchelt DR: Environmental enrichment exacerbates amyloid plaque formation in a transgenic mouse model of Alzheimer disease. J Neuropathol Exp Neurol 2003;62: 1220-1227.

101 Cotman CW, Berchtold NC: Exercise: a behavioral intervention to enhance brain health and plasticity. Trends Neurosci 2002; 25:295-301.

102 Shi Y, Kirwan P, Smith J, Robinson HP, Livesey FJ: Human cerebral cortex development from pluripotent stem cells to functional excitatory synapses. Nat Neurosci 2012;15:477-486 